\title{
ÇANKIRI-ÇORUM HAVZASI OLIGOSEN KUMTAŞLARININ PETROGRAFISI VE PROVENANSI, YOZGAT
}

\author{
Hilal DOKUZ (ORCID: 0000-0002-0490-0503) $)^{1 *}$ \\ ${ }^{1}$ Ahievran Üniversitesi, Mühendislik Fakültesi, Jeoloji Mühendisliği Bölümü, Kırşshir
}

Geliş / Received: 14.11.2018

Kabul / Accepted: 20.12.2018

\begin{abstract}
$\ddot{\mathbf{O Z Z}}$
Çankırı-Çorum Havzası Oligosen istifleri, özellikle Yerköy (Yozgat) ile Delice (Kırıkkale) arasında yanal devamlılı̆g olan ve kırmızı rengi ile kolay haritalanabilen karasal kırıntılılardan oluşur. Litolojisi çoğunlukla konglomera, kumtaşı ve çamurtaşı olup, yer yer evaporit seviyeleri bulundurur. Fasiyes analizlerine göre alüvyon yelpazesi, akarsu ve göl ortamlarında çökelmiştir. Önceki çalışmalarda İncik, Deliceırmak, Kızılöz ve Kızılırmak Fm. olarak haritalanan birimin yaşı Oligosen, Geç Oligosen, Oligosen-Erken Miyosen olarak verilmektedir. Omurgalı fosil, palinoloji ve göreceli stratigrafi verileri Oligosen-Erken Miyosen aralığını gösterse de alt ve üst sınırların nerelere kadar uzandığı belli değildir. Öte yandan, Kırşehir Masifi’nin yükselmesi ve yüzeylenmesi, daha genel ifade ile İç Anadolu'dan denizin çekilmesi ve bölgenin tektonostratigrafik evrimi için bu istifin stratigrafisinin belirlenmesi ve petrografisinin ortaya konulmasi gereklidir.

$\mathrm{Bu}$ çalışmanın konusunu oluşturan Yozgat-Yerköy civarında yer alan Oligosen yaşlı kumtaşlarının bileşenleri kuvars, plajiyoklaz, alkali feldispatlar (ortoklas, mikroklin), mikalar (muskovit, biyotit), sedimanter (karbonat, çört), magmatik ve metamorfik kayaç parçaları (şist) ile ağır minerallerden (epidot, zirkon, hornblend) oluşmaktadır. Petrografik olarak incelenen birimler Q-F-L üçgen diyagramında [1]'a göre arkoz ve litik arkoz, [2]'a göre arkozik arenit olarak sınıflandırılmıştır. Provenans çalışmaları kapsamında Qt-F-L üçgen diyagramları kullanılarak kumtaşlarının kaynak alanlarıyla ilgili çıkarımlarda da bulunulmuştur. Buna göre Yozgat-Yerköy civarı kumtaşlarının ana kaynağı çoğunlukla temel yükselim ve yay geçişi bölgesine düşmektedir.
\end{abstract}

Anahtar kelimeler: Oligosen, İncik Fm, Kumtaşı, Sedimanter Petrografi, Orta Anadolu.

\section{PETROGRAPHY AND PROVENANCE OF OLIGOCENE SANDSTONES OF ÇANKIRI ÇORUM BASIN, YOZGAT}

\begin{abstract}
Oligocene sequences of Çankırı-Çorum Basin are composed of terrestrial clastic sediments between Yerköy (Yozgat) and Delice (Kırkkkae), which are laterally persistent and easily mapped owing to their reddish color. The lithologies generally consist of conglomerate, sandstone, and mudstone while evaporite levels can be seen on some parts. According to facies analyses, they generally deposited in alluvial fan, river and lake environments. The age of the unit which named as İncik Formation, Deliceırmak Formation, Kızılöz Formation and Kızılırmak Formation in previous studies is presented as Oligocene, Late Oligocene, Oligocene-Early Miocene. However vertebrate fossils, palynology and stratigraphy data point out Oligocene-Early Miocene interval, the lower and upper limits are not obvious. On the other hand, to obtain the age of uplift and cropped up of Kırşehir Massive or withdrawal of sea from Central Anatolia and tectonostratigraphic evolution of the region, in general, it is necessary to obtain the sequence and petrographic features. ${ }^{1}$
\end{abstract}

"Corresponding author / Sorumlu yazar. Tel:+90 3122303402 ; e-mail: hengin @ ankara.edu.tr 
The Oligocene sandstones form Yozgat-Yerköy vicinity which composes the subject of this study consist of quartz, plagioclase, alkali feldspar (orthoclase, microcline), mica (muscovite, biotite), sedimentary (carbonate, chert), magmatic and metamorphic (schist) rock fragments and heavy minerals (epidote, zircon, hornblende). The units which investigated petrographically are classified on Q-F-L triangular diagrams as arkose and lithic arkose according to [1] and as arkosic arenite according to [2]. In the concept of provenance studies, the source field of sandstones is evaluated by using Qt-F-L triangular diagrams. Consequently, the main source of sandstones from Yozgat-Yerköy vicinity is located on basin uplift and transit, on arc regions.

Keywords: Oligocene, İncik Formation, Sandstone, Sedimentary Petrography, Central Anatolia

\section{GíRIŞ}

Oligosen dönemi, birçok açıdan önemli bir dönem olarak kabul edilmektedir. Tetis Okyanusu'nun hakimiyet sürdüğü geniş bir alan, Eosen'den itibaren Avrasya ve Afrika kıtalarının yakınlaşması nedeniyle yükselmeye başlamıştır. Oligosen Dönemi'nde Pireneler'den Zagros Dağları'na uzanan Alpin orojenezi ile yükselim devam etmiştir. Oluşan bu dağ kuşağı, ılıman geçen Eosen Dönemi iklim koşullarının Oligosen Dönemi'nde soğuk ve kuru bir iklime doğru evrilmesinden sorumludur [3]. Anadolu Levhası'nın yükselmesi Avrupa ve Asya kıtaları arasında kara köprüsü oluşmasını sağlamıştır. Bu kara köprüsü birçok memeli türü için bir göç yolu oluşturmuştur. Anadolu Levhası'nda, Oligosen'nin karasal koşullarının etkilerinin görüldüğü en önemli alanlardan biri ÇankırıÇorum Havzası'dır. Bu havzanın güney kesiminde bulunan çökellerin ayrıntılı olarak çalışılmamış olması önemli bir eksikliktir. Oligosen çökellerinin depolandığı dönemde Kırşehir Masifi kayaçlarının yüzeylenmiş olup olmadığı önemli bir soru işareti oluşturmaktadır. Masifin bu dönemde yüzeyde olup olmadığı Oligosen Döneminin kırıntılı kayaçlarının çakıl ve mineral içerikleri ayrıntılı olarak incelenerek belirlenebilecektir.

Petrografik ve jeokimyasal incelemeler çeşitli araştırmacılar tarafından sedimanter kayaçlarda da provenans ve paleotektonik ortam yorumlamalarında kullanılmaktadır [4-6]. Ayrıca kimyasal bozunma, silisiklastik çökellerin başlıca element jeokimyasını ve mineralojisini güçlü bir şekilde etkilemektedir [7-9]. Bu nedenle Kimyasal Alterasyon Indeksi (CIA; [6]), Kimyasal Günlenme Indeksi (CIW; [10]) ve Plajiyoklaz Alterasyon Indeksi (PIA; [9]) gibi kantitatif ölçümlerden, kimyasal bozunma derecesini değerlendirmek amcıyla yararlanılmaktadır [9].

$\mathrm{Bu}$ çalışmada, Çankırı-Çorum Havzasının Yerköy, Yozgat civarında bulunan kumtaşlarının petrografi ve provenans incelemeleri yapılarak kumtaşlarının isimlendirilmesi ve kaynak alan yorumlamasının yapılması amaçlanmıştır. Aynı zamanda CIA-CIW-PIA hesaplamaları yapılarak kumtaşlarının kimyasal bozunma derecesinin belirlenmesi de amaçlanmıştır.

\section{MATERYAL ve METOT}

Çalışma alanında belirlenen problemlerin çözümlenebilmesi amacıyla literatür çalışmalarının akabinde arazi çalışmaları gerçekleştirilmiştir. Bu çalışmalar kapsamında Yerköy, Yozgat civarında 5 adet Ölçülü Stratigrafik Kesit (ÖSK) ölçülmüştür. Bu ÖSK'lardan fasiyes ayırtlamaları yapılmıştır. Arazide elde edilen örneklerin Ankara Üniversitesi Jeoloji Mühendisliği İnce Kesit Laboratuvarları'nda ince kesitleri yapılmıştır. Bu ince kesit örneklerinin petrografik incelemeleri ve mineral sayımları Ankara Üniversitesi, Jeoloji Mühendisliği, Optik Mineraloji ve Petrografi Laboratuvarları'nda gerçekleştirilmiştir. Kayaçların kimyasal bozunma dereceleri hakkında yaklaşımda bulunmak amacıyla ana ve iz element miktarlarını belirlemek üzere jeokimyasal analizler (XRF analizleri) Ankara Üniversitesi Yerbilimleri Uygulama ve Araştırma Merkezi (YEBİM) Laboratuvarları'nda yapılmıştır. Petrografik incelemelerde elde edilen mineral yüzdeleri [1] ve [2] Q-F-L grafikleri ile değerlendirilmiştir. Jeokimyasal analizlerde elde edilen veriler hem CIA-CIW-PIA grafiklerinde, hem de [11] ile [4] tarafından önerilen üçgen diagramları kullanılarak yorumlanmıştır. Provenans yorumlamalarında ise [5] Qt-FL üçgen grafiği kullanılmıştır.

\section{JEOLOJÍK ORTAM ve STRATIGRAFİ}

Çalışma alanı Yozgat ilinin 35 km güneybatısında bulunan Yerköy ilçesi dolayındaki Oligosen kumtaşlarını kapsamaktadır (Şekil 1). Bölge, Çankırı-Çorum Havzası'nın güney kesimini oluşturmaktadır. Çankırı-Çorum Havzası'nın çökelleri daha önce farklı çalışmacılar tarafından incelenmiştir [12-14]. Ancak Havzanın güney kesiminin Oligosen stratigrafisi henüz aydınlatılamamıştır. 


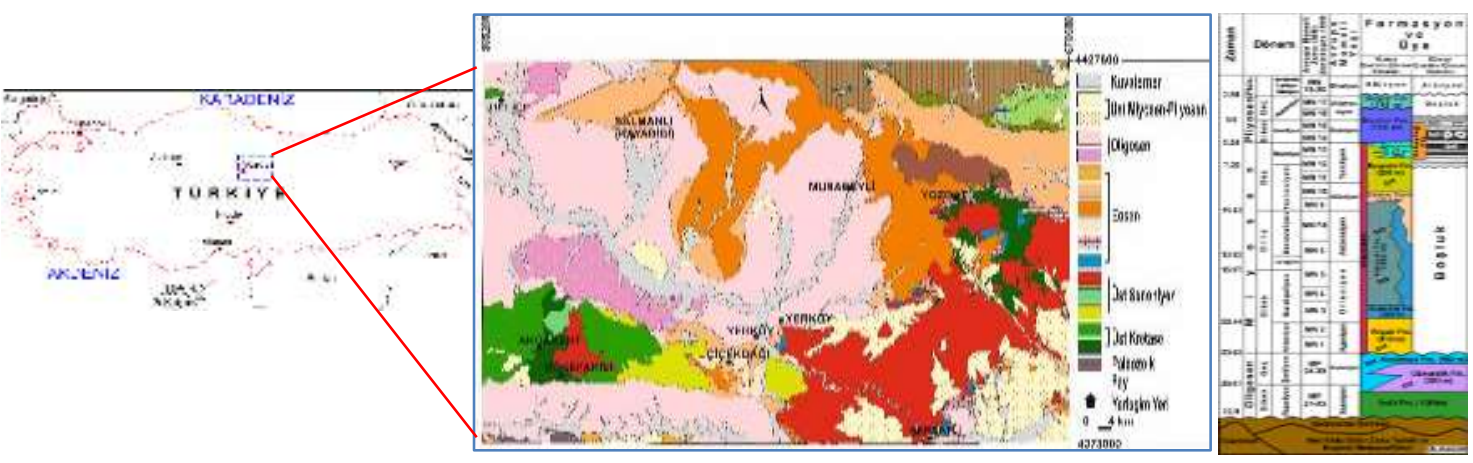

Şekil 1. Çalışma alanının yer bulduru, jeoloji haritası ve stratigrafik kesiti ([14, 19, 20]'den değiştirilerek)

Havzanın temelini Kırşehir Masifi'nin magmatik ve metamorfik kayaçlar ile Tetis Okyanusu'nun kalıntılarını temsil eden ofiyolitik kayalar oluşturmaktadır [15]. Metamorfikler Kalkanlıdă Formasyonu, Tamadă Formasyonu ve Bozçaldağ Formasyonlarından oluşmaktadır [16]. Mesozoik öncesi olarak yaşlandırılan birimler genel olarak gnays, biotitşist, metakuvarsit ve kuvarsist, mermer-şist ve gnays ile mermer ve metaçörtlerden meydana gelir [16]. Bu birimler Kırşehir masifinin magmatik kayaçları tarafından kesilmektedir. Çankırı-Çorum Havzası'nın en alt çökel birimleri Maastrihtiyen ve Paleosen yaşlı türbiditleridir [17, 18, 14]. Oligosen yaşlı formasyonlar, İncik, Güvendik ve onunla yanal geçişli olan Kızılırmak Formasyonlarından oluşmaktadır. İncik Formasyonu masif-tabakalı konglomeraları, paralel ve çapraz tabakalı kumtaşlarını, tabakalı silttaşlarını ve masif çamurtaşlarını içermektedir [14]. İncik Formasyonu yaş verilebilecek bir fosil bulgusuna rastlanmadığından, alt ve üstünde yer alan birimlerle stratigrafik ilişkilerine göre Erken Oligosen olarak yaşlandırılmıştır [14]. İncik formasyonu daha genç Güvendik [13]ve Kızılırmak Formasyonları tarafından üzerlenir. Güvendik Formasyonu, tabakalı jipsler, bazı nodüler anhidritler ile laminalı kiltaşları içerir [14]. Bu birimler, üzerlerine gelen Miyosen çökelleri ile uyumsuzdur. Bu birimlerin üzerine Pliyosen yaşlı Bozkır ve Deyim Formasyonları gelmektedir. Havzanın en genç birimleri Kuvaterner çökelleridir.

\section{TARTIŞMA}

\subsection{Kumtaşlarının Petrografisi}

Çalışma alanındaki kumtaşlarına ait mineral oranları; Kuvars \%6-35, Feldispat \%35-87, Kayaç Parçası, \%5-45, arasında değişen miktarlara sahiptir. Bunlardan kuvarslar monokristalin ve polikristalin kuvarslardan, feldispatlar çoğunlukla plajiyoklazlar, ayrıca alkali feldispatlardan ortoklaz, mikroklin ve sanidin ile volkanik, metamorfik ve sedimanter kayaç parçalarından oluşmaktadır. Kumtaşları mika minerallerinden muskovit ve biyotitleri de bulundurmaktadır. Kalsit ve hornblend mikroskobik incelemelerde gözlenen diğer minerallerdir. Ayrıca zirkon, apatit ve glokofan gibi ağır minerallere de rastlanmıştır (Şekil 2). Petrografik çalışmalar neticesinde kumtaşı örnekleri [1] ve [2]'un Q-F-L grafiğginde sınıflandırılmıştır (Şekil 3). [2]'a göre örneklerimiz arkozik arenit alanına dağılmıştır. [1] göre ise örnekler arkoz ve litik arkoz alanındadır.

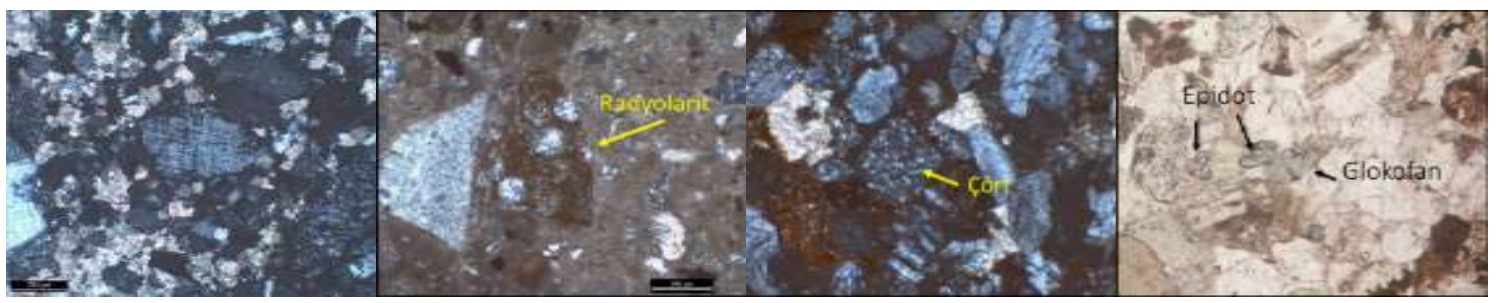

Şekil 2. Kumtaşlarında bulunan hafif ve ağır mineraller ve volkanik, metamorfik, sedimanter kayaç parçaları 


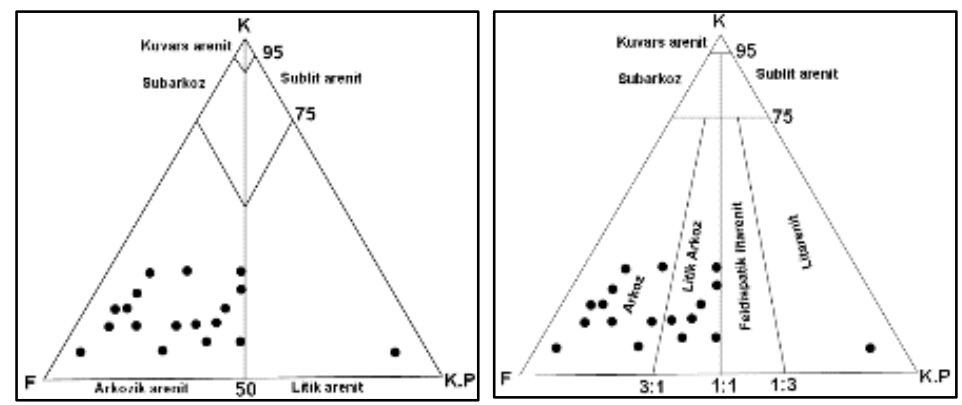

Şekil 3. Q-F-L üçgen grafiğinde kayaçların dağılımı [1, 2]

\subsection{Kumtaşlarının Bozunma ve Bozuşması}

Kuvars ve feldispat gibi kayaç yapıcı mineraller, üst kıtasal kabuğun yaklaşık \%70'ini oluşturmaktadır [21]. Kuvars ihmal edildiğinde feldispatlar bozunma için belirleyici mineraller olarak kabul edilirler. Kırıntılı sedimater kayaçlarda günlenme (weathering) ve bozuşma olayları (altaresyon) kayaç jeokimyasını etkileyen olaylardır. Kimyasal Alterasyon İndeksi (CIA) kırıntılı sedimanların provenans kayalarının kimyasal günlenmesinin tahmini ölçülebilir derecesini sunar [18]. CIA $=100 x\left[\mathrm{Al}_{2} \mathrm{O}_{3} /\left(\mathrm{Al}_{2} \mathrm{O}_{3}+\mathrm{CaO} *+\mathrm{Na}_{2} \mathrm{O}+\mathrm{K}_{2} \mathrm{O}\right)\right]$ eşitliğiyle hesaplanmaktadır. CIA, 80-100 arasında aşırı şiddetli; 50-80 arası şiddetli alterasyonu, $\leq 50$ ise bozunmanın şiddetli olmadığını gösterir. Kimyasal Günlenme İndeksi (CIW) esas olarak feldispatların killere dönüşümünün ölçüsüdür [7]. $\mathrm{CIW}=100 x\left[\mathrm{Al}_{2} \mathrm{O}_{3} /\left(\mathrm{Al}_{2} \mathrm{O}_{3}+\mathrm{CaO} *+\mathrm{Na}_{2} \mathrm{O}\right)\right]$ eşitliğiyle hesaplanmaktadır. CIW, 50'den az ise günlenme olmadığını, 50-70 arasında günlenmenin zayıf olduğunu ve 100'e yaklaştıkça kuvvetli kimyasal günlenmeyi gösterir.

Plajioklaz Alterasyon İndeksi (PIA)'ini CIW'nin alternatifi olarak kullanılır [9]. Plajioklaz'ın klastik kayaçlarında bol olmasından ve dayanımının düşük olmasından dolayı PIA alterasyon göstergesi olarak kullanılabilmektedir. Hesaplamalarda PIA $=100 \times\left[\left(\mathrm{Al}_{2} \mathrm{O}_{3}-\mathrm{K}_{2} \mathrm{O}\right) /\left(\mathrm{Al}_{2} \mathrm{O}_{3}+\mathrm{CaO}+\mathrm{Na}_{2} \mathrm{O}-\mathrm{K}_{2} \mathrm{O}\right)\right]$ eşitliğ kullanılmaktadır. PIA, 50'den düşük ise bozunma olmadığını, 100'e doğru yükseldiğinde ise günlenme etkisinin artışını göstermektedir. Çalışmada elde edilen jeokimyasal veriler CIA-CIW-PIA grafiklerinde değerlendirilmiştir. Şekil 4'te çalışma alanına ait kayaçların provenans kayalarının düşük-orta şiddetli bir bozuşmaya maruz kaldıkları görülmektedir. Üç indeksin de birbirleri ile uyumlu olduğu görülmektedir. Şekil 5'de verilen üçgen diyagramlar dikkate alındığında alterasyon değerlerinin düşük-orta olduğu görülmektedir. Değerlerin volkanik kayaçlara benzer değerler sunduğu ve Plajiyoklaz-K-feldispat çizgilerinin altında yoğunlaştığı görülmektedir.

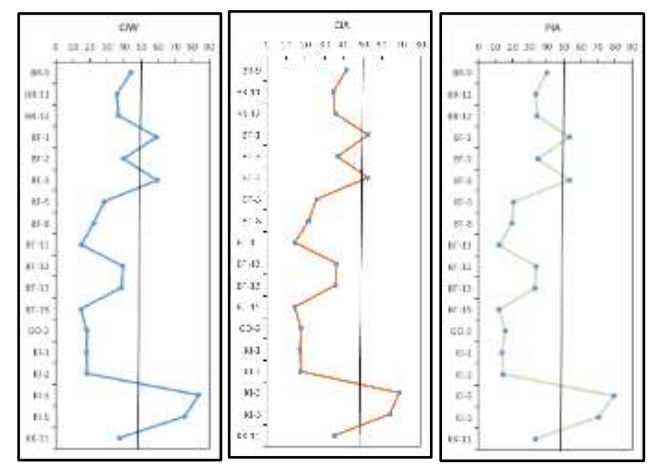

Şekil 4. Kumtaşlarının CIW-CIA-PIA grafikleri

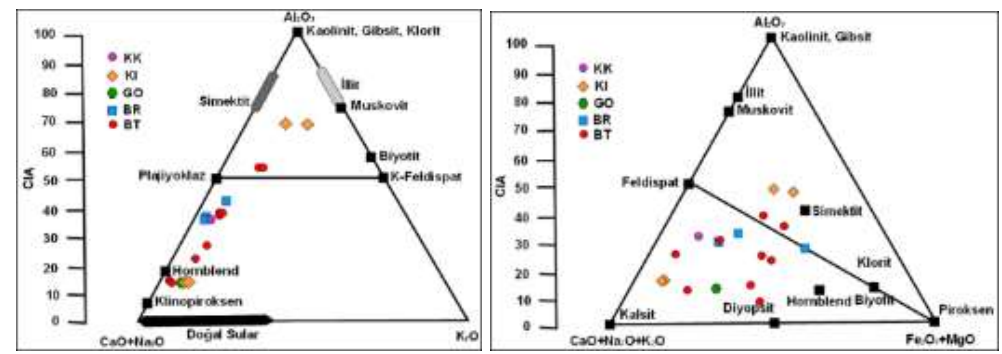

Şekil 5. CIA ve bazı ana oksit dağılım üçgen grafikleri $[10,4]$ 


\subsection{Tektonik Konum}

Petrografik ve jeokimyasal incelemeler klastik kayaçlarda provenans ve jeotektonik ortamın anlaşılmasında kullanılmaktadır [4-6]. Kumtaşlarının bileşimi, sedimanter provenansın karakteristiğinden, çökelme havzasındaki tortul süreçlerden ve havzayı kaynak alana bağlayan dağılma yollarından etkilenmektedir. Kaynak alan ve havza arasındaki temel ilişkiler, tektonik olarak farklı türlerdeki kumtaşlarının dağılımını kontrol eden levha tektoniği ile yönetilir. [22] ve [23], kuvarsça zengin kayaçların tipik olarak pasif kıta kenarı ile ilişkili olduğunu, kuvarsça fakir kayaçların çoğunlukla magmatik ada yaylarından volkanojenik türevi olduğunu ve ortaç kuvars içeriğine sahip kayaçların aktif kıtasal kenarlar veya diğer orojenik kuşaklarla ilişkili olduğunu göstermiştir (Şekil 6).

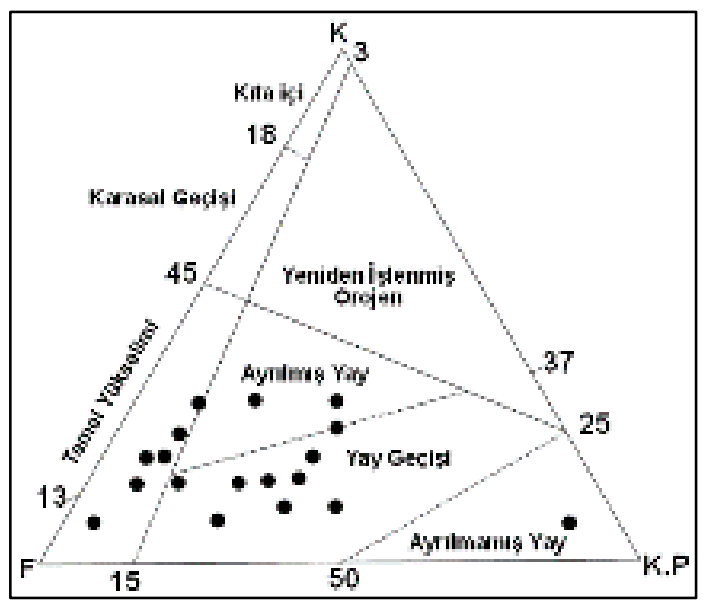

Şekil 6. Kumtaşlarının tektonik ortamlara göre dağılımı [5]

\section{SONUÇLAR}

Çankırı-Çorum Havzası Oligosen kumtaşları petrografik ve jeokimyasal olarak incelenmiştir. Kumtaşları [1]'e göre arkoz ve litik arkoz, [2]'a göre arkozik arenit karakterindedir. Kayaçların mineral bileşimleri, K-feldispatlar, plajiyoklazlar, kuvars, kalsit, biyotit, muskovit, hornblend mineralleri ile zirkon, apatit ve glokofan minerallerinden oluşmaktadır. Ayrıca magmatik, metamorfik ve sedimanter kayaç parçaları bulunmaktadır. Feldispatların ve kayaç parçalarının bol miktarda bulunması beslenmenin kısa mesafeli kaynaklardan sağlandığına işarettir. Kayaçların bağlayıcı türü, kalsit, sparit, kil, Fe ve Si’dur. CIA, CIW ve PIA değerleri birbiriyle uyumludur. Bu verilere göre kumtaşlarının alterasyon değerleri zayıf-orta şiddette değişmektedir. Qt-F-L üçgen grafiğine göre kumtaşları provenansı temel yükselimi-yay geçişi alanına karşılık gelmektedir. Bu durum, beslenmenin kapanan Tetis Okyanusu'ndan türeyen kayaçlar tarafından sağlandığını ve havza yükselmesinin depolanma esnasında etkili olduğunu göstermiştir Kayaçların alterasyon şiddetinin düşük-orta şiddette olması da kırıntılı malzemenin uzun mesafeler taşınmadı̆̆ı yorumuna katkı sağlamaktadır.

\section{TEŞEKKÜR}

Yazar, çalışmalarının her aşamasındaki bilimsel yönlendirmeleri için danışmanı Prof. Dr. Nizamettin KAZANCI'ya ve geliştirici önerileri için Doç. Dr. Alper Gürbüz’e teşekkürlerini sunar.

\section{KAYNAKLAR}

[1] FOLK, R.L., Petrology of Sedimentary Rocks, Hemphill Publishing Company, Austin, 1980.

[2] PETTIJOHN, F.J., POTTER, P.E. VE SIEVER, R., Sand and Sandstone. Wiley, New York, 1- 168, 1973.

[3] SUN J., NI X., Bİ S. WU W., YE, J, MENG J., WINDELN, B. F., "Synchronous turnover of flora, fauna, and climate at the Eocene-Oligocene Boundary in Asia", Nature, Scientific report 4, 7463, 1-6, 2014.

[4] NOCKOLDS, S.R., "Average chemical compositions of some igneous rocks", Geological Society of America Bulletin, 65, 1007-1032, 1954.

[5] DICKINSON, W.R., SUCZEK, C.A., "Plate tectonics and sandstone compositions", AAPG Bulletin 63, 2164-2182, 1979. 
[6] BHATIA, M.R., "Plate tectonics and geochemical composition of sandstones", Journal of Geology, 91, 611-627, 1983.

[7] NESBITT, H.W., YOUNG, G.M., "Prediction of some weathering trends of plutonic and volcanic rocks based on thermodynamic and kinetic considerations", Geochimica and Cosmochimica Acta, 48, 1523$1534,1984$.

[8] MCLENNAN, S.M., HEMMING, S., MCDANIEL, D.K., HANSON, G.N., Geochemical approaches to sedimentation, provenance, and tectonics. In: M.J. Johnsson ve A. Basu, (eds.), Process Controlling the Composition of Clastic Sediments: Geological Society of America, Special Paper, (pp. 21-40), 1993.

[9] FEDO, C.M., NESBITT, H.W., YOUNG, G.M., "Unravelling the effects of potassium metamorphism in sedimentary rocks and paleosols, with implications for paleoweathering conditions and provenance and tectonic setting", Geochimica et Cosmochimica Acta, 54, 1061-1081, 1995.

[10] HARNOIS, L., "The CIW index: a new chemical index of weathering”, Sedimentary Geology, 55, 319322, 1988.

[11] MCLENNAN, S.M., TAYLOR, S.R., HEMMING, S.R., Composition, differentiation, and evolution of continental crust: constraints from sedimentary rocks and heat flow. In: Brown, M. ve Rushmer, T. (eds). Evolution and Differentiation of the Continental Crust: Cambridge University Pres., 2003.

[12]KARADENIZLİ, L., Çankırı-Çorum Havzası'ndaki Orta Eosen-Erken Miyosen tortullarının sedimantolojisi. Ankara Üniversitesi Fen Bilimleri Enstitüsü, Doktora Tezi, 259s., 1999.

[13] KAYMAKÇI, N., Tectono-stratigraphical evolution of the Çankırı Basin (Central Anatolia Turkey), Geologia Ultraiectina 190, (pp. 1-247), 2000.

[14] KARADENIZLİ, L., "Oligocene to Pliocene palaeogeographic evolution of the Çankır1-Çorum Basin, Central Anatolia, Turkey”, Sedimentary Geology, 237, 1-29. 2011.

[15] ŞENGÖR, A.M.C., YILMAZ, Y., "Tethyan evolution of Turkey: A plate tectonic approach", Tectonophysics, 75, 181-241, 1981.

[16] SEYMEN, İ., "Tamadağ (Kaman-Kırşehir) çevresinde Kaman grubunun ve onunla sınırdaş oluşukların karşılaştırılmalı tektonik özellikleri”, TJK, 26, 89-98, 1983.

[17] NORMAN, T., "Ankara-Yahşıhan bölgesinde Üst Kretase-Alt Tersiyer istifinin stratigrafisi”, TJK, 15, $180-276,1972$.

[18] KAZANCI, N., VAROL, B., "Development of a mass flow-dominated fan-delta complex and associated carbonate reefs within a transgressive Paleocene succession, Central Anatolia, Turkey", Sedimentary Geology 68, 261-278, 1990.

[19] DÖNMEZ, M., BİlGIN, Z.R., AKÇAY, A.E., KARA, H., YERGÖK, A.H., ESENTÜRK, K. 1/100.000 ölçekli açınsama nitelikli Türkiye Jeoloji Haritaları, Kırşehir-İ31 paftası, No: 46, MTA, Ankara. 2005.

[20] AKÇAY, A.E., DÖNMEZ, M., KARA H., YERGÖK, A.F., ESENTÜRK K. 1/100 000 ölçekli açınsama nitelikli Türkiye Jeoloji Haritaları Serisi, Yozgat-İ33 Paftası. MTA, Ankara, 80, 1-16, 2007

[21] NESBITT H.W., YOUNG G.M., "Early Proterozoic climates and plate motions inferred from major element chemistry of lutites", Nature, 299, 715-717, 1982.

[22] CROOK, K. A W., "Lithogenesis and geotectonics: the significance of compositional variations in flysch arenites (greywackes)", Society of Economic Paleontologists and Mineralogists special publication 19, 304-310, 1974.

[23] SCHWAB, F.L., "Framework mineralogy and chemical composition of continental margin-type sandstone”, Geology, 3, 487-490, 1975.2 